\title{
Academic motivation among senior students majoring in rehabilitation related professions in China
}

Huiling $\mathrm{Hu}^{1^{*}}$ and Hongmei Luo ${ }^{2}$

\begin{abstract}
Objective/background: In mainland China, most universities offer general rehabilitation curricula rather than specialized curricula. The purpose of the current study is to investigate senior students' academic motivation for rehabilitation and examine whether it varies among different curriculum structures, students' gender, specific interests, and parental average education level.

Methods: This cross-sectional study recruited both senior students in general and those who specialized in rehabilitation curricula using an online survey. The Academic Motivation Scale (AMS) was used to measure academic motivation.

Results: The response rate was 74.68\%, and 59 senior students in total (male: 34.48\%; female: 65.52\%) were analyzed. Twenty-nine (50.00\%) students were from a general rehabilitation curriculum at Guangxi Medical University, and the rest $(n=29,50.00 \%)$ were from a specialized curriculum at West China Medical School of Sichuan University. The overall average academic motivation score was 30.96 \pm 5.92. Students in the specialized rehabilitation curriculum (32.85 \pm 6.26$)$ showed a significantly higher academic motivation score than those in the general rehabilitation curriculum ( $29.10 \pm 5.00, p<0.05)$. Male $(31.13 \pm 5.67)$ and female $(30.88 \pm 6.12)$ students had equally high scores $(p=0.88)$. Students who had specific interests $(29.81 \pm 4.73)$ and those who did not (24.69 \pm 4.92$)$ shared the same academic motivation ( $\mathrm{t}=2.00, p=0.06$ ).

Conclusions: Senior rehabilitation science students in specialized curricula have higher levels of academic motivation than those in general curricula. There was no significant difference in academic motivation scores based on students' gender, specific interests, or parental average education levels.
\end{abstract}

Keywords: Academic motivation, Medical education, Motivation, Rehabilitation education, Rehabilitation students

\section{Introduction}

\section{Rehabilitation education in China}

Currently, China's educational training in rehabilitation is still in the developing stage. The academic standards of most rehabilitation curricula in China are not able

\footnotetext{
*Correspondence: hhl0628@126.com

${ }^{1}$ Department of Rehabilitation Medicine, The Second Xiangya Hospital of Central South University, Renmin Middle Road NO.139, Furong district, Changsha, Hunan, China

Full list of author information is available at the end of the article
}

to meet the minimum requirements proposed by the World Federation of Occupational Therapists (WFOT), the World Confederation for Physical Therapy (WCPT), or other international therapist federations [1]. High academic motivation is a critical component of successful learning performance and scholarly achievement [2]. China has been left behind in regard to carrying out regular rehabilitation education, such as undergraduate rehabilitation and postgraduate education [3]. Undergraduate rehabilitation education did not start until 2001, 
and the related college education (diploma only) has only been implemented for just over 20 years [4]. The education system of rehabilitation is not perfect, and the training methods and quality are quite different from those found in other countries. Most universities still provide the following two curricula: rehabilitation therapy science (bachelor's degrees) or rehabilitation technology (diploma only), such as Hunan University of Tradition Chinese Medicine and Guangxi Medical University. Both are general professional curricula with a comprehensive curriculum structure. Only a few colleges and universities have a rehabilitation therapy science curricula with a specific curriculum structure of physiotherapy or occupational therapy, such as Kunming Medical University and West China Medical School of Sichuan University [5].

Additionally, rehabilitation is not the first choice for a number of students. It is a universal phenomenon in China that some students in the rehabilitation profession also apply for other majors, but they often fail to enroll in the others. These students have poor recognition of the major and show a low level of professional identity [6]. The complex circumstances make academic motivation among Chinese students majoring in rehabilitation more complicated.

\section{Academic motivation}

Motivation allows learners to participate in learning activities and maintain their learning status [7, 8]. Academic motivation is a student's desire (as reflected in his or her approach, persistence, and level of interest) regarding academic subjects when the student's competence is judged against a standard of performance or excellence [9]. This concept will affect the deep processing of investment information. Additionally, it relates to self-efficacy, goal setting, and the generation of achievement expectations [10]. During the past 30 years, motivation has been a high-frequency word in the field of educational psychology. Some articles have pointed out that academic motivation does not seem to be a valid predictor of grade point average (GPA) [11]. However, there are still immense benefits of motivation because it is helpful with numerous learning outcomes directly relating to academic achievement [12], along with positive self-concept [13] and persistence [14]. There are significant consequences resulting from motivation, such as academic performance and scholarly achievement, intention to drop out, and absenteeism [2]. Of the three kinds of motivation (intrinsic motivation, extrinsic motivation, and amotivation), intrinsic motivation is considered more significant in education. This factor can make a better change in regard to promoting efficient learning and creativity. There are three subscales of intrinsic motivation, to know, toward accomplishment and to experience stimulation. Intrinsic motivation leads people to perform activities with internal emotions [15]. For example, people will feel a sense of joy, curiosity, happiness, interest, or other internal emotions. However, extrinsic motivation makes people keep the result in mind, regardless of the outcome is. The result can be a positive award, or it can also be a negative penalty [16]. There are also three subfields of extrinsic motivation; identified, introjected and external regulation. Amotivation occurs when a student has no intention to display the behavior [15]. If the student does not display academic behavior voluntarily and there is no reason why the behavior should be displayed, then it is considered that the student feels amotivated [17]. Different results correspond to each type of academic motivation; thus, motivation can predict students' academic achievements and learning performance, participation and learning attitude, and the ability to stick to a learning goal [18].

It is advised to develop academic motivation to guide students to cultivate a habit of deep learning and obtain a good grade, especially for health care-related professions students [19].

\section{Potential influential factors of academic motivation}

Evidence shows a list of the potential influencing factors of academic motivation, including students' gender, specific interests, and parental average education level. Overall, these factors make up over $20 \%$ of the difference in academic motivation [20]. In addition, Lyndon and his colleagues [21] suggested that curriculum structures can also affect students' motivation. To improve students' academic performance and psychological status, researchers have examined these motivational profiles. They have indicated that faculty and staff in school could adjust educational activities, teaching strategies of regulation and curriculum structures to make students more self-determined [22].

However, no research has focused on academic motivation and associated factors for students in the rehabilitation-related profession in China. Thus, the purpose of the current study is to investigate rehabilitation students' academic motivation in China. Based on the above previous research, we want to examine whether differences exist in students' academic motivation among students' gender, specific interests, parental average education level, and curriculum structures. The following are our hypotheses: male and female students share the same academic motivation; students who have specific interests have higher academic motivation; students whose parental average education level is higher have higher academic motivation; students who major in specialized 
have higher academic motivation general curriculum students.

\section{Method \\ Design and participants}

We used a cross-sectional descriptive survey carried out between October and November of 2020. The target population for this study consisted of senior students majoring in rehabilitation-related professions. Through 3 years of learning in their curricula, senior students have already acquired a fundamental and relatively comprehensive understanding of their major and have benefited from the different curriculum structures. Researchers obtained a convenience sample by taking a cross-section of senior students at two universities, namely, Guangxi Medical University and West China Medical School of Sichuan University. Guangxi Medical University was selected because the researcher graduated from there, and the school offers a set of generalized rehabilitation curricula for a bachelor's degree in science of rehabilitation. West China Medical School of Sichuan University was selected because it provides specialized PT (physical therapy) or OT (occupational therapy) curricula. It was the first university to recruit rehabilitation profession students in 1997, and it subdivided the general profession into two more specialized curricula, namely, PT and OT, in 2008. These two curricula settings were accredited by the WCPT and WFOT in 2013 and 2014, respectively [23].

\section{Instruments}

In this study, academic motivation was measured by the Academic Motivation Scale. The survey was conducted online using Wenjuanxing, an online survey management tool, via WeChat. It is convenient to communicate and share questionnaires through WeChat in China. The survey was divided into three sections: participants' informed consent, demographic information including gender, grade, the full name of the profession, parental educational level, the subfield of the profession, and specific interests (only for general curriculum students), and the Academic Motivation Scale.

The Academic Motivation Scale (AMS) is most widely used as an assessment instrument in academic motivation [22]. It contains 28 items rated on a 7-point Likert scale. The AMS is rooted in the self-determination theory, a theory which focuses on the approach to human motivation and personality [24]. This theory applies traditional empirical method and organismic metatheory to explore the psychological mechanisms relating to inner resources for personality and behavioral self-regulation [17]. Supported by the self-determination theory, the AMS is a valid and reliable way to assess students' motivation and now has been applied in recent decades in high school and college education [22]. .The college version of the AMS has been used to assess university students' intrinsic motivation, extrinsic motivation, and amotivation toward education. AMS appears to be among the most popular academic motivation measures for college students [25]. The scale's developers have contended that the AMS is cross-culturally valid [26]. The AMS in this study was adapted from the Chinese translated version by Zhang, Li, Li, Li \& Zhang [2].

\section{Procedures}

After the Creighton University Institutional Review Board approved this proposal, coordinated faculty from Guangxi Medical University and Sichuan University helped distribute the questionnaires. They sent the questionnaire link to the senior students via WeChat. Before the participants were allowed access to the survey, they had to acknowledge their consent by reading the consent information on the top of the online survey link. Only when all the items on the questionnaire were answered could it be considered a valid response. The survey was kept anonymous, and 4 weeks were provided for survey completion. The coordinated faculty reminded the participants about the deadline.

\section{Data analysis}

To answer the research questions, we used simple descriptive statistics, frequency testing and hypothesis testing to analyze demographics collected from the survey. For differences in academic motivation based on the profession's curriculum structures, a specific interest in the subfield of rehabilitation, and gender, we use independent samples t-test. For differences in academic motivation based on parental educational level, we used one-way analysis of variance (ANOVA). The significance level was set at 0.05 .

\section{Results}

We received 59 responses from 79 (74.68\%) selected senior students from a total of two universities. Twentynine out of 31 (93.55\%) students at Sichuan University responded to the questionnaire, and all responses were valid for analysis. Thirty out of 48 (62.50\%) students at Guangxi Medical University responded to this questionnaire. However, one response was invalid because the participant all chose the first answer option for 28 question items and finished the questionnaire within a much shorter time than average. Thus, a total of 58 responses were used for data analysis.

Table 1 shows the demographic information of the 58 valid responses. Exactly half of these participants were 
Table 1 Demographics of the valid responded senior students

\begin{tabular}{llll}
\hline Items & Categories & N & Percentage (\%) \\
\hline Gender & Male & 20 & 34.48 \\
Your profession & Female & 38 & 65.52 \\
& Rehabilitation (General) & 29 & 50.00 \\
& Rehabilitation (PT) & 22 & 37.93 \\
& Rehabilitation (OT) & 7 & 12.07 \\
Your parents' education level (the highest) & Primary education or lower & 11 & 18.97 \\
& Secondary education & 27 & 46.55 \\
& College education & 11 & 18.97 \\
& Undergraduate education & 8 & 13.79 \\
Regions of university & Postgraduate education or higher & 1 & 1.72 \\
& Sichuan & 29 & 50.00 \\
& Guangxi & 29 & 50.00 \\
\hline
\end{tabular}

Table 2 Demographics of rehabilitation (general) senior students' subfield of interest

\begin{tabular}{lll}
\hline Categories & N & Percentage (\%) \\
\hline Physical therapy & 10 & 40.00 \\
Pediatric & 5 & 20.00 \\
Respiratory therapy & 3 & 12.00 \\
Speech therapy & 3 & 12.00 \\
Traditional Chinese Medicine & 1 & 4.00 \\
Sports injury & 1 & 4.00 \\
Occupational therapy & 1 & 4.00 \\
Post-natal rehabilitation & 1 & 4.00 \\
\hline
\end{tabular}

from the general rehabilitation science curriculum at Guangxi Medical University. The other half were from the rehabilitation curriculum with a specialized subfield at Sichuan University $(n=29,50 \%)$. As the table shows, the higher education level, the fewer parents.
Table 2 shows the subfields of interest of the senior students majoring in rehabilitation science (general). Most of these senior students cultivated an interest in at least one subfield $(n=25,86.21 \%)$. Only a few did not have a specific interest, and they did not care which rehabilitation subfields they worked on in the future $(n=4$, $13.79 \%)$.

Table 3 shows the distributions of the seven subscales of the AMS. All the subscales of the AMS have high mean scores except for the subscale of amotivation. Senior students from two kinds of curricula had good academic motivation with an average score of 30.96 .

Table 4 shows that, on average, students from the specialized rehabilitation curriculum had significantly higher academic motivation scores $(32.85 \pm 6.26)$ than those from a general rehabilitation curriculum $(29.10 \pm 5.00)$ $(\mathrm{t}=2.50, p=0.02)$. However, from the table the difference based on parental education levels was not significant $(\mathrm{F}(3,54)=2.48, p=0.07)$. Similarly, there was no significant difference between males $(31.13 \pm 5.67)$ and females

Table 3 The detailed information of the subfield of AMS

\begin{tabular}{|c|c|c|c|c|c|c|}
\hline & \multirow[t]{2}{*}{ Max } & \multirow[t]{2}{*}{ Min } & \multirow[t]{2}{*}{ Mean } & \multirow[t]{2}{*}{ Std. Dev } & \multicolumn{2}{|l|}{$95 \% \mathrm{Cl}$} \\
\hline & & & & & Lower bound & Upper bound \\
\hline Intrinsic motivation-to know & 7.00 & 4.00 & 5.65 & 0.96 & 5.39 & 5.90 \\
\hline Intrinsic motivation-toward accomplishment & 7.00 & 2.75 & 5.48 & 1.14 & 5.18 & 2.78 \\
\hline Intrinsic motivation-to experience stimulation & 7.00 & 3.50 & 5.56 & 1.00 & 5.30 & 5.82 \\
\hline Extrinsic motivation- identified & 7.00 & 3.50 & 5.75 & 0.96 & 5.50 & 6.00 \\
\hline Extrinsic motivation-introjected & 7.00 & 1.75 & 4.96 & 1.29 & 4.62 & 5.30 \\
\hline Extrinsic motivation- external regulation & 7.00 & 3.75 & 5.78 & 0.97 & 5.52 & 6.03 \\
\hline Amotivation & 6.00 & 1.00 & 2.21 & 1.27 & 1.87 & 2.54 \\
\hline Total points & 41.00 & 18.50 & 30.96 & 5.92 & 29.40 & 32.52 \\
\hline
\end{tabular}

Each rating scale is $1-7$ 
Table 4 AMS difference

\begin{tabular}{|c|c|c|c|c|c|c|}
\hline & \multirow[t]{2}{*}{ Frequency (n) } & \multirow[t]{2}{*}{ Mean } & \multirow[t]{2}{*}{ Std. Dev } & \multicolumn{2}{|l|}{$95 \% \mathrm{Cl}$} & \multirow[t]{2}{*}{$P$} \\
\hline & & & & Lower bound & Upper bound & \\
\hline Gender & & & & & & $0.88^{a}$ \\
\hline Male & 20 & 31.13 & 5.67 & 28.48 & 33.78 & \\
\hline Female & 38 & 30.88 & 6.12 & 28.86 & 32.89 & \\
\hline Curriculum structure & & & & & & $0.02^{\mathrm{a} *}$ \\
\hline Specialized & 29 & 32.82 & 6.26 & 30.43 & 35.20 & \\
\hline General & 29 & 29.10 & 5.00 & 27.20 & 31.01 & \\
\hline Parental education & & & & & & $0.07^{b}$ \\
\hline Elementary school & 11 & 27.61 & 4.65 & 24.49 & 30.73 & \\
\hline Middle and high school & 27 & 32.10 & 5.23 & 30.03 & 34.17 & \\
\hline College & 11 & 29.43 & 7.21 & 24.59 & 34.27 & \\
\hline University graduate or higher & 9 & 33.50 & 6.21 & 28.72 & 38.28 & \\
\hline Have specific interests or not & & & & & & $0.06^{\mathrm{a}}$ \\
\hline Yes & 25 & 29.81 & 4.73 & 27.86 & 31.76 & \\
\hline No & 4 & 24.69 & 4.92 & 16.86 & 32.52 & \\
\hline Intrinsic motivation & & & & & & $0.02^{\mathrm{a} *}$ \\
\hline Specialized & 29 & 17.62 & 3.26 & 16.38 & 18.86 & \\
\hline General & 29 & 15.76 & 2.39 & 14.85 & 16.67 & \\
\hline Extrinsic motivation & & & & & & $0.01^{\mathrm{a} *}$ \\
\hline Specialized & 29 & 17.48 & 3.10 & 16.31 & 18.66 & \\
\hline General & 29 & 15.47 & 2.10 & 14.68 & 16.27 & \\
\hline Amotivation & & & & & & $0.65^{\mathrm{a}}$ \\
\hline Specialized & 29 & 2.28 & 1.45 & 1.73 & 2.84 & \\
\hline General & 29 & 2.12 & 1.10 & 1.71 & 2.54 & \\
\hline
\end{tabular}

$\mathrm{a}$ independent samples t-test

b one-way analysis of variance

* significant difference

$(30.88 \pm 6.12)(t=0.15, p=0.88)$. There was also no significant difference based on whether the senior students had specific interests $(29.81 \pm 4.73)$ or $\operatorname{not}(24.69 \pm 4.92)$ $(\mathrm{t}=2.00, p=0.06)$. For further study, we analyzed the three different subfields of the AMS between the specialized and general curriculum students. The analysis showed that specialized curriculum students not only had higher levels of intrinsic motivation (17.62 \pm 3.26$)$ than did general curriculum students $(15.76 \pm 2.39)$ $(\mathrm{t}=2.48, p=0.02)$ but also had higher levels of extrinsic motivation $(17.48 \pm 3.10)$ than did those from general the rehabilitation curriculum $(15.47 \pm 2.10) \quad(t=2.89$, $p=0.01)$. However, they had a similar level of amotivation $(\mathrm{t}=0.46, p=0.65)$.

\section{Discussion}

Although the AMS has been widely used in western counties, little research discusses academic motivation and associated factors for rehabilitation-related profession students in China. Our results show that students enrolled in a specialized rehabilitation curriculum have higher academic motivation scores than those of general rehabilitation curriculum students. No difference was found based on students' gender and their parental education level.

The source of motivation is different, and the impact may be individualized [27]. Specifically, the evidence shows that students' academic motivation varies due to the curriculum structures [21]. Our study supports this view, and we find that specialized curriculum students have higher levels of academic motivation. We consider this outcome to be related to the accreditation of the curriculum settings. The WFOT and the WCPT have detailed curriculum requirements, including content, teaching, learning and assessment strategies, and skill development for educational curricula. The WCPT has accredited six curricula providing a bachelor's degree in physical therapy or a Bachelor of Science (BSc) in rehabilitation therapy (Physical Therapy) in China [28]. Similarly, the WFOT has approved six curricula providing a Bachelor of Occupational Therapy or a Bachelor of Science in 
occupational therapy in China [29]. One of our survey sites, the West China Medical School of Sichuan University, received accreditation from both groups. According to the education minimum standards and the guidelines of WFOT and the WCPT, autonomous learning and lifelong learning are emphasized, such as "Graduates should be autonomous learners with developed lifelong learning skills and an ability to engage in continuing professional development" [30, 31]. We think these criteria may lead to the fact that students in West China Medical School of Sichuan University have higher intrinsic academic motivation than those from Guangxi Medical University. The Academy of Guangxi Medical University has also reflected on their curriculum setting and has been trying to refer to the educational requirements of the WCPT and the WFOT to provide specialized rehabilitation curricula in the future [32]. Specifically, we found that differences are significant in the subscales of intrinsic motivation (to-know and to-experience stimulation) and extrinsic motivation (identified and external regulation). Students at West China Medical University of Sichuan University have better intrinsic motivation (to-know and to-experience), so they have more pleasure, satisfaction, and stimulating sensations of experience while learning. This study finding is consistent with those of a previous study [33]. Similar to students in international business professionals, senior students at West China Medical University of Sichuan University value external regulations, as they want to give a more positive image to family and friends [34]. Similarly, we found students in West China Medical School of Sichuan University have higher extrinsic motivation scores on the identified and external regulation subscales. Stated another way, these students tend to value their study's significance and consciously accept the regulatory process [35]. Most likely, they benefit from small class teaching models, and each of them has one senior undergraduate tutor [23]. Interestingly, the latest research reveals that virtual gamification enhances intrinsic motivation, which is a potential application in future online learning [36].

There are multitudinous factors but students' perspective, gender, and the average education level of their parents are considered the most critical predictors of academic motivation [20]. Other factors include students' family support, such as family socioeconomic status and parental expectations [37]. Female students seem to outperform males in many aspects of academic achievement, and gender differences in motivation are considered a part of the reason why [38]. However, another study reported that male students have higher motivation levels than female students [39]. Our study found no significant difference in academic motivation based on students' gender or their parental education level. These findings are different from those of previous studies. We may ascribe the differences to the regional and time disparities. Currently, we emphasize more than ever the education equality of men and women. Factors including gender bias and parental educational level may not affect students' academic motivation so much. Another potential reason is that our sample size is insufficient.

We consider generalizing our results among students studying in general and specialized rehabilitation curricula in China. There are only six occupational therapy and physiotherapy curricula accredited by international organizations thus far. Academic motivation varies based on curriculum structure among students majoring in rehabilitation science. It is recommended that educators arrange specific curricula to enhance medical students' motivation for research [40]. For rehabilitation students, educators may also consider transforming the curriculum structure from the general rehabilitation curriculum to a specialized one in the rehabilitation science field's undergraduate education. Considering this point further, educators may deliberate the improvement of not only the curriculum structure but also classroom teaching and examinations to help students have both better intrinsic and external motivation [24].

\section{Limitations and recommendations}

The academic motivation scale we used has been found to be cross-culturally valid in many education professions; nevertheless, it has not been applied among rehabilitation students. Therefore, it is necessary to validate this scale in the further study.

Moreover, our survey was conducted in two different universities; thus, there may be regional and university differences. For example, the West China Medicine School of Sichuan University recruits students who receive higher grades on their college entrance examination compared to those at Guangxi Medical University. This may affect the result and lead the students at Sichuan University to have higher academic motivation scores.

Additionally, the low number of responses received from Guangxi Medical University practitioners may result in a sample bias. The participants in our study were all senior students who were struggling during their clinical practicum period. They already have a hectic schedule in their last academic year. On the other hand, the questionnaires we used were self-assessments. Thus, if the participants were engaged in their work these days, the 28-item questionnaires may have seemed too overwhelming for them. If this was the case, then there will be inaccuracies in their scores. Additionally, the sample is very small, and thus, it may be hard to generalize to the population. 
Other potential factors that were not included on the list may also affect academic motivation, including the understanding of their major and why they chose it. Future interviews can use semi-structured methods to discover more probable affecting factors related to academic motivation.

\section{Conclusion}

Our survey study demonstrates the academic motivation of senior students from both general and specialized rehabilitation curricula in China. The response rate in our study $(73.42 \%)$ is considerably higher than the average rate achieved by most electronic surveys (32.6\%) [41]. Senior rehabilitation science students in specialized curricula have higher levels of academic motivation than those in general curricula. Furthermore, there is no significant difference found in the academic motivation scores based on students' gender, specific interests, or average parental education levels. Administrators and experts in the field of education should make efforts to promote specialized education and deliberate about how to draw on the experience of the different educational structures in their own context.

\section{Abbreviations}

AMS: The Academic Motivation Scale; WFOT: World Federation of Occupational Therapists; WCPT: World Confederation for Physical Therapy; GPA: Grade point average; PT: Physical therapy; OT: Occupational therapy.

\section{Supplementary Information}

The online version contains supplementary material available at https://doi. org/10.1186/s12909-021-03016-9.

\section{Additional file 1.}

\section{Acknowledgements}

We sincerely thank Keli Mu and Yongyue Qi from Creighton University, Jian Li from Beijing Normal University, Yonghong Yang from West China Medicine School of Sichuan University and Jianwen Xu, Jing Wei, and Min Li from Guangxi Medical University and Jinlong Cui from Xiangya Boai Rehabilitation Hospital, without whose help the present research would not have been carried out so fluently. Additionally, we deeply appreciate the help of the senior students with rehabilitation-related professions who took part in this study.

\section{Authors' contributions}

$\mathrm{HH}$ and $\mathrm{HL}$ collaborated with each other on the literature review. The two authors discussed the topic and developed the final idea. The two authors cooperated and did the literature review together. HL screened out the articles that had reference value. $\mathrm{HH}$ read each of the articles. The two authors discussed the literature and wrote the introduction section together. Statistical processing was also performed by the two authors. $\mathrm{HH}$ designed the questionnaire and $\mathrm{HL}$ collected the data. The two authors discussed the statistical methods, and $\mathrm{HH}$ accomplished the data processing step. $\mathrm{HL}$ summarized the data. After communication of the results, $\mathrm{HH}$ wrote the discussion section. All authors reviewed the manuscript. The author(s) read and approved the final manuscript.

\section{Funding}

There was no funding for this study.
Availability of data and materials

Data and other relevant material will be provided for noncommercial use by the corresponding author.

\section{Declarations}

Ethics approval and consent to participate

The study was approved by the Creighton University Institutional Review Board. The reference code is 2001290-01.

\section{Consent for publication}

Before participants were allowed access to the survey, they had to acknowledge their consent by reading the consent information on the top of the online survey link.

\section{Competing interests}

Both authors declared no potential conflicts of interest with respect to the research, authorship, and/or publication of this article.

\section{Author details}

${ }^{1}$ Department of Rehabilitation Medicine, The Second Xiangya Hospital of Central South University, Renmin Middle Road NO.139, Furong district, Changsha, Hunan, China. ${ }^{2}$ Department of Rehabilitation Medicine, Tongji Hospital, Tongji Medical College, Huazhong University of Science and Technology, Wuhan, China.

Received: 22 June 2021 Accepted: 4 November 2021

Published online: 17 November 2021

References

1. Yan C, Cuihuan P. Comparative analysis of undergraduate education curriculum of rehabilitation therapy in Chinese medical colleges and universities. Chin J Rehabil Med. 2010;25(10):992-5.

2. Zhang B, Li YM, Li J, Li Y, Zhang H. The Revision and Validation of the Academic Motivation Scale in China. Journal of Psychoeducational Assessment. 2016;34(1):15-27.

3. Feng G, Jinglong C, Na L. Current situation and development of occupational therapy education in China -- learning experience of MOT course in Hong Kong polytechnic university. Chin J Rehabil. 2018;33(1):67-70.

4. Yang $H$, Chen $X$, Wang $X, Y u X$, Huang Y. Discussion on the problems and solutions in the training of rehabilitation students. Chin Med Modern Dist Educ China. 2019;17(24):158-60.

5. Xie L, Xu T, Liu Y, Xia N, Tang Z, Wang Y, et al. Research on the current situation of rehabilitation education in China. Chin J Rehabil. 2019;34(10):557-60

6. Jiang M, Zeng W, Wang S, Wang L, LI S. Investigation and analysis of professional identity and cognition of undergraduates of rehabilitation therapy in colleges and universities. Smart Healthcare. 2019;5(34):39-42.

7. De Naeghel J, Van Keer H, Vansteenkiste M, Rosseel Y. The relation between elementary students' recreational and academic reading motivation, reading frequency, engagement, and comprehension: a selfdetermination theory perspective. J Educ Psychol. 2012;104(4):1006-21.

8. Guilloteaux MJ, Dörnyei Z. Motivating language learners: a classroomoriented investigation of the effects of motivational strategies on student motivation. Tesol Q. 2008;42(1):55-77.

9. Kevin McGrew. Beyond IQ: A model of Academic Competence \& Motivation (MACM) 2008 [28 Feb 2020]. Available from: http://www.iapsych. com/acmcewok/Academicmotivation.html.

10. Stover J, de la Iglesia G, Boubeta A, Liporace M. Academic motivation scale: adaptation and psychometric analyses for high school and college students. Psychol Res Behav Manag. 2012;5:71-83.

11. John Walter Carroll. Academic Motivation of Degree-seeking Undergraduate Students at a For-profit University in the United States[D]. Texas: The University of Texas at Austin; 2016.

12. Chow SJ, Yong BC. Secondary School Students'Motivation and Achievement in Combined Science US-China. Educ Rev. 2013;3:213-28.

13. Seaton M, Parker P, Marsh HW, Craven RG, Yeung AS. The reciprocal relations between self-concept, motivation and achievement: juxtaposing 
academic self-concept and achievement goal orientations for mathematics success. Educ Psychol. 2014;34(1):49-72.

14. Vansteenkiste M, Zhou M, Lens W, Soenens B. Experiences of autonomy and control among Chinese learners: vitalizing or immobilizing? J Educ Psychol. 2005;97(3):468-83.

15. Kişoğlu M. An examination of science high school students' motivation towards learning biology and their attitude towards biology lesson. Int J Higher Educ. 2018;7:151.

16. Ergün M. SInıfta Motivasyon; 2003. p. 134-48.

17. Ryan RM, Deci EL. Self-determination theory and the facilitation of intrinsic motivation, social development, and well-being. Am Psychol. 2000;55(1):68-78.

18. Utvaer BK, Haugan G. The academic motivation scale: dimensionality, reliability, and construct validity among vocational students. J Voc Educ Train. 2016;6:17-45.

19. Kusurkar RA, Ten Cate TJ, Vos CM, Westers P, Croiset G. How motivation affects academic performance: a structural equation modelling analysis. Adv Health Sci Educ Theory Pract. 2013;18(1):57-69.

20. Taghipour HA, Gilaninia S, Jalali M, Azizipour H, Razaghi SJR, Mousavian SJ. Standardizing of academic motivation scale. J Basic Appl Sci Res. 2012;2:1186-92

21. Lyndon MP, Henning MA, Alyami H, Krishna S, Yu T-C, Hill AG. The impact of a revised curriculum on academic motivation, burnout, and quality of life among medical students. J Med Educ Curric Dev. 2017:4:2382120517721901.

22. Orsini C, Binnie V, Evans P, Ledezma P, Fuentes F, Villegas MJ. Psychometric validation of the academic motivation scale in a dental student sample. J Dent Educ. 2015;79(8):971-81.

23. Undergraduate medical education 2020 [15 Oct 2020]. Available from: https://wcsm.scu.edu.cn/cms/jwb/contents/472/905.html.

24. Ten Cate TJ, Kusurkar RA, Williams GC. How self-determination theory can assist our understanding of the teaching and learning processes in medical education. AMEE guide no. 59. Med Teach. 2011;33(12):961-73.

25. Cokley K. A confirmatory factor analysis of the academic motivation scale with black college students. Meas Eval Couns Dev. 2015;48(2):124-39.

26. Vallerand RJ, Pelletier LG, Blais MR, Briere NM, Senecal C, Vallieres EF. On the assessment of intrinsic, extrinsic, and Amotivation in education: evidence on the concurrent and construct validity of the academic motivation scale. Educ Psychol Meas. 1993;53(1):159-72.

27. Pardee R. Motivation theories of Maslow, Herzberg, McGregor \& McClelland. A Literature Review of Selected Theories Dealing with Job Satisfaction and Motivation. 1990

28. Accredited programmes 2020 [9 Nov 2020]. Available from: https://world. physio/what-we-do/education/accreditation/programmes.
29. WFOT Approved education Programmes 2020 [9 Nov 2020]. Available from: https://www.wfot.org/programmes/education/wfot-approvededucation-programmes.

30. Education / World Physiotherapy 2020 [Available from: https://world. physio/what-we-do/education.

31. Education /WFOT 2020 [Available from: https://www.wfot.org/progr ammes/education.

32. Wu M, Long Y. Discussion on the course construction of bachelor degree of rehabilitation therapy science profession in Guangxi Medical University. China Contin Med Educ. 2016;8(11):35-6.

33. Vallerand RJ, Pelletier LG, Blais MR, Briere NM, Senecal C, Vallieres EF. The Academic Motivation Scale: A Measure of Intrinsic, Extrinsic, and Amotivation in Education. Educ Psychol Meas. 1992;52:1003.

34. Vicente-Ramos W, Silva B, Merino S, Lazo S, Mejia C. Academic Motivations of Pregrade Students in the Choice of International Business Career. Int J Higher Educ. 2020;9:85.

35. Kusurkar R, Croiset G, Kruitwagen C, ten Cate O. Validity evidence for the measurement of the strength of motivation for medical school. Adv Health Sci Educ Theory Pract. 2011;16(2):183-95.

36. Xu J, Lio A, Dhaliwal H, Andrei S, Balakrishnan S, Nagani U, et al. Psychological interventions of virtual gamification within academic intrinsic motivation: a systematic review. J Affect Disord. 2021;293:444-65.

37. Gao H, Ou Y, Zhang Z, Ni M, Zhou X, Liao L. The relationship between family support and e-learning engagement in college students: the mediating role of e-learning normative consciousness and behaviors and self-efficacy. Front Psychol. 2021;12:573779.

38. Butler R. Motivation in educational contexts: does gender matter? Adv Child Dev Behav. 2014;47:1-41.

39. Wu H, Li S, Zheng J, Guo J. Medical students' motivation and academic performance: the mediating roles of self-efficacy and learning engagement. Med Educ Online. 2020;25(1):1742964.

40. Ommering BWC, van Blankenstein FM, Waaijer CJF, Dekker FW. Future physician-scientists: could we catch them young? Factors influencing intrinsic and extrinsic motivation for research among first-year medical students. Perspect Med Educ. 2018;7(4):248-55.

41. Watt S, Simpson C, McKillop C, Nunn V. Electronic course surveys: does automating feedback and reporting give better results? Assess Eval High Educ. 2002:27(4):325-37.

\section{Publisher's Note}

Springer Nature remains neutral with regard to jurisdictional claims in published maps and institutional affiliations.
Ready to submit your research? Choose BMC and benefit from:

- fast, convenient online submission

- thorough peer review by experienced researchers in your field

- rapid publication on acceptance

- support for research data, including large and complex data types

- gold Open Access which fosters wider collaboration and increased citations

- maximum visibility for your research: over $100 \mathrm{M}$ website views per year

At BMC, research is always in progress.

Learn more biomedcentral.com/submissions 